\title{
ANALISIS PROMOSI PENJUALAN GOPAY DENGAN METODE SOCIAL NETWORK ANALYSIS DI MEDIA SOSIAL TWITTER
}

\author{
Dewinta Srinanda $^{1)}$, Kristina Sisilia ${ }^{2)}$, Yahya Perangingangin ${ }^{3) 凶}$ \\ Jurusan Administrasi Bisnis, Fakultas Komunikasi Bisnis, Universitas Telkom
}

\begin{abstract}
Info Artikel Abstrak
Diserahkan Juni 2020

Terdapat peningkatan sebesar Rp 1.668.659.367,00 atau 117\% dalam volume transaksi elektronik tahun 2018 Diterima Juni 2020

Diterbitkan September dimana sebelumnya peningkatan maximalnya adalah $40 \%$. Penyedia layanan transaksi elektronik dengan 2020

Kata Kunci:

Promosi penjualan, Diskon, Cashback, Social Network Analysis (SNA), Twitter

pengguna paling aktif adalah Gopay dengan promosi penjualan menjadi strategi pemasaran yang paling aktif digunakan. Media sosial menjadi tempat banyak orang memposting kegiatan mereka dan cara untuk mengakses data tersebut adalah menggunakan API (Application program interface). Tujuan dari studi ini untuk mengetahui promosi penjualan Gopay di Twitter dan analisis jaringan sosial Gopay dalam bentuk pemeran kunci penyebaran informasi tentang promosi penjualan dengan menggunakan metode kuantitatif, jenis penelitian deskriptif dan metode kuota sampling. Teknik analisis data menggunakan Analisis Jaringan Sosial yang memvisualisasikan jaringan dengan memanfaatkan perangkat lunak Gephi serta menentukan pemeran kunci. Berdasarkan hasil penelitian, Gopay memiliki node 4.021 dan edge 2.358 yang berarti tidak semua node saling terhubung. Sehingga pengguna yang berbicara tentang promosi penjualan Gopay dinilai kurang aktif dalam percakapan. Nilai diameter jaringan Gopay adalah 14, semakin kecil diameter maka informasi lebih cepat disebarluaskan. Tingkat keterhubungan Jaringan sosial Gopay adalah 1.175, berarti satu node hanya memiliki 1 hubungan dengan node lain dalam jaringan. Dan rata - rata nilai panjang jalur adalah 5,07 menunjukkan jarak yang ditempuh informasi untuk mencapai node lain adalah 5 hop.
\end{abstract}

(C) 2020 Indonesia

\footnotetext{
Alamat Korespondensi:

Fakultas Komunikasi Bisnis, S1 Administrasi Bisnis

Telkom University

E-mail: dewinta.srinanda@gmail.com

kristina@telkomuniversity.ac.id

yahyaperanginangin@telkomuniversity.ac.id
} 


\section{Pendahuluan}

Perkembangan teknologi khususnya interne saat ini memberikan kesempatan kemudahan bagi semua orang dari berbagai latar belakang untuk melakukan aktivitasnya. Seperti kemudahan dalam bidang transportasi, dahulu ketika seseorang ingin menggunakan ojek harus menghampiri tempat ojek berada, namun kini ojek sudah bisa dipesan melalui aplikasi di smartphone. Begitu pula dengan kegiatan transaksi, sekarang jika seseorang ingin mengirim sejumlah uang tertentu dapat melalui ponsel, tentu saja dengan koneksi internet yang stabil. Tidak perlu mengantri panjang di Bank. Masih banyak kemudahan lain yang dapat ditemui dalam kegiatan sehari - hari yang mengubah perilaku terdahulu.

Tentunya dengan fenomena tersebut mengakibatkan adanya suatu perubahan yang dapat disebut dengan pergeseran perilaku konsumen, di masa lalu suatu kegiatan membutuhkan waktu yang lama untuk dilakukan, sekarang kegiatan dapat dilakukan lebih cepat dan fleksibel. Berikut data mengenai salah satu kemudahan yang ditemui saat ini yaitu transaksi di Indonesia. (Sumber : https://www.bi.go.id/)

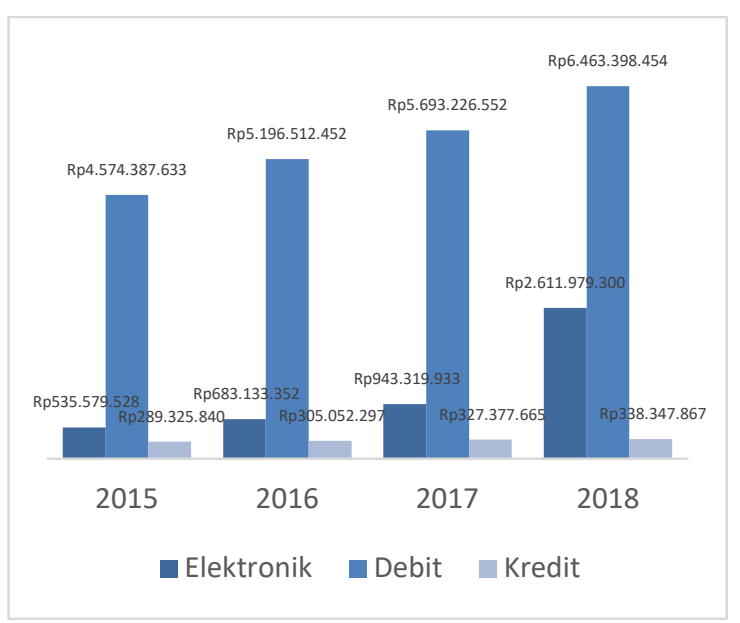

Gambar 1 Volume Transaksi Pembayan

Berdasarkan gambar transaksi pembayaran, ketiga jenis transaksi diatas memang mengalami peningkatan yang stabil. Menariknya, kenaikan cukup signifikan terjadi pada transaksi elektronik yaitu sebesar $117 \%$ dengan total transaksi sebesar Rp 1.668.659.367 dimana tahun - tahun sebelumnya tingkat kenaikan maximal hanya $40 \%$. Hal ini terjadi karena adanya pergeseran perilaku konsumen dalam bertransaksi.

Pergeseran perilaku juga mengubah kebiasaan seseorang dimana dahulu untuk berbagi kegiatan yang telah lampau hanya bisa dalam bentuk fisik seperti album foto. Kini orang - orang menggunakan media sosial untuk berbagi segala kegiatannya karena dapat diakses kapan saja dan dimana saja selama ada internet. Begitu pula perusahaan yang menggunakan media sosial untuk berbagi informasi mengenai hal - hal yang ditawarkan kepada konsumen. Semua data di media sosial ini dapat dilihat dan diakses oleh mereka yang memenuhi syarat tertentu.

Fenomena ini membuktikan bahwa semua elemen membuat Internet memfasilitasi pekerjaan, karena internet adalah alat yang membuat seseorang bisa mendapatkan informasi cepat (Zainuri, et al., 2015). Internet dibutuhkan karena mekanisme pembayaran dituntut untuk selalu mengakomodasi kebutuhan masyarakat dalam hal mentransfer dana dengan cepat, aman dan efisien. Kemudian inovasi teknologi pembayaran bermunculan dengan sangat cepat untuk memberikan jawaban dengan berbagai fasilitas kenyamanan. Pembayaran merupakan komponen penting dalam setiap aktivitas transaksi perdagangan, baik barang maupun jasa. Keberhasilan sistem pembayaran dapat mendukung pertumbuhan ekonomi suatu negara.

Ranah penyimpanan digital, yang dikenal sebagai Electronic Wallet atau E-wallet, telah populer di Indonesia sejak 2017. Sejak saat itu, penyedia layanan penyimpanan digital telah mencapai 38 perusahaan resmi yang dilisensikan oleh Bank Indonesia. Meningkatnya persaingan dapat dilihat dari poster, Billboard, spanduk, selebaran mengenai diskon dan Cashback dari penyedia platform pembayaran elektronik dalam makanan, minuman, pakaian, dll (Anggraeni , 2019)

Menurut penelitian iPrice, situs yang membandingkan harga, voucher, kupon, dan promo mengatakan bahwa Gojek dengan fitur Gopay adalah e-wallet yang memiliki pengguna paling aktif di antara semua e-wallet yang ada di Indonesia. Artinya Gopay adalah penyedia $E$ wallet terbaik di Indonesia. Dalam penelitian ini, Iprice berkolaborasi dengan perusahaan analisis data, App Annie. Dengan indikator jumlah pengguna aktif, hal ini dapat menunjukkan bahwa Gopay melakukan kegiatan komunikasi pemasaran atau biasa disebut promosi yang lebih aktif sehingga banyak orang menggunakan Gopay.

Media sosial adalah cara komunikasi yang biayanya rendah dan tingkat interaktivitasnya tinggi. Sehingga dapat membantu perusahaan melaksanakan kegiatan pemasaran lebih efisien daripada alat pemasaran tradisional seperti televisi, radio, Surat Kabar (Alawan, et al., 2017). Ada 4 media sosial yang digunakan oleh Gopay, yaitu: YouTube, Twitter, Instagram, dan Facebook. Namun, hanya Twitter yang 
digunakan dalam penelitian karena berdasarkan teknik analisis data yang digunakan, Twitter adalah media sosial yang proses izinnya tidak rumit.

Gopay menggunakan \#GoPaypromo untuk menyebarluaskan informasi tentang promosi yang mereka lakukan. Berdasarkan pengamatan dengan menggunakan \#GoPaypromo pada akun Gopay untuk mengetahui jenis promosi yang dilakukan oleh Gopay, dua kata yang paling sering dicuitkan adalah Cashback dan Diskon. Sehingga strategi promosi Gopay yang paling aktif dibicarakan adalah promosi penjualan dalam bentuk Cashback dan diskon.

Teknik analisis data yang digunakan pada penelitian ini adalah Social Network Analysis, teknik ini dikhususkan untuk menganalisis data data pada media sosial. Penelitian ini didukung oleh penelitian - penelitian terdahulu mengenai interaksi pengguna media sosial tentang suatu topik pembicaraan. Salah satunya jurnal yang berjudul "Dynamic Social Network Analysis Untuk Analisa Interaksi User Di Media Sosial Mengenai Bisnis E-Commerce (Studi Kasus: Lazada, Tokopedia Dan Elevenia)" (Bratawisnu \& Alamsyah, 2018). Lazada memiliki nilai properti jaringan sosial yang lebih tinggi mengenai node yang menandakan bahwa banyak user yang membicarakan Lazada di media sosial, edge yang membuktikan banyak interaksi antar user mengenai Lazada di media sosial, dan Average Degree yang menunjukkan setiap aktor dalam jaringan tersebut memiliki banyak hubungan sehingga akan memperluas penyebaran informasi mengenai e-commerce Lazada.

Serupa dengan Bratawisnu tetapi berbeda objek penelitian, (Aini \& Alamsyah, 2016) dalam "Analisis Pada Peringkat Top Brand Menggunakan Jejaring Sosial Percakapan Dengan Social Network Analysis ( Studi Kasus Pada Smartphone Samsung, Blackberry, Nokia, Iphone Di Indonesia)" menyimpulkan Samsung unggul pada 2 properti yaitu Average Degree dan clustering coefficient. Berarti dengan unggul pada Average Degree, Samsung memiliki banyak jumlah link yang menghubungkan node maka penyebaran informasi mengenai Samsung akan semakin cepat. Sedangkan clustering coefficient menunjukan hubungan node yang ada dalam jaringan Samsung itu kuat.

Dua penelitian tersebut menggunakan API (Application Programming Interface) yang merupakan syarat agar penelitian dapat dilakukan. API adalah seperangkat protokol yang memberikan izin untuk mengakses data twitter yang dipublikasikan secara publik, sehingga Tweet yang bersifat pribadi tidak akan dapat diakses.

Dengan begitu identifikasi masalah dalam penelitian ini adalah bagaimana jaringan sosial promosi penjualan gopay di Twitter? bagaimana hasil analisis jaringan social gopay?

\section{Metode}

Metode penelitian adalah langkah - langkah spesifik (tindakan, tahap, pendekatan langkah demi langkah dan lain - lain) yang harus diambil dan dijalankan dalam urutan tertentu selama penelitian.

Jenis penelitian ini adalah kuantitatif karena jenis data berupa numerik dan statistik, dengan metode deskriptif di mana peneliti akan menganalisis hasil jaringan sosial. Metode sampling yang digunakan adalah quota sampling karena sebelum melakukan crawling data peneliti membatasi tweet, reply, retweet dan mention sebanyak 800.000 per jam karena terdapat aturan limit per hour saat melakukan crawling data.

Teknik pengumpulan data pada penelitian jaringan sosial disebut dengan crawling data yaitu kegiatan menambang (mining) seluruh tweet, reply, retweet dan mention yang berkaitan dengan kata kunci "Cashback Gopay dan Diskon Gopay" sesuai dengan ketentuan API (Application Programming Interface) menggunakan software RStudio.

Data yang diperoleh di Twitter adalah data sekunder, yang disebut User generated content (UGC). UGC adalah data yang umumnya dapat dilihat oleh pengguna lain, dimana isinya mengandung sejumlah kreativitas dan dibuat oleh orang yang bukan profesional dalam bidang ini. SNA memiliki beberapa properti jaringan untuk memetakan hubungan yang sangat membantu untuk meningkatkan penciptaan management knowledge di organisasi (Newman, 2018).

Adapun beberapa properti jaringan pada SNA antara lain:

1) Nodes. Merupakan representasi aktor yang berada dalam jaringan (Hanneman \& Riddle, 2005). Pada gambar 2.5, terdapat empat aktor yang melakukan interaksi yang dilambangkan dengan nodes 1,2,3,4.

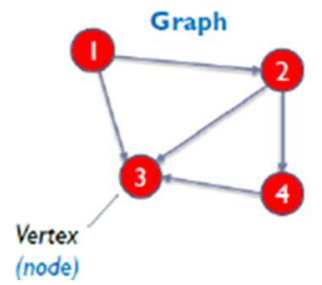

Gambar 2 Nodes pada SNA 
2) Edges. Merupakan representasi hubungan antar aktor atau entitas yang terjadi dalam network (Hanneman \& Riddle, 2005). Pada gambar 2.6, terdapat lima edges (garis) pada jaringan sosial yang melambangkan terjadi lima hubungan antar 4 aktor (nodes).

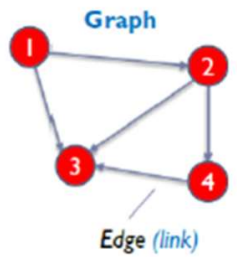

\section{Gambar 3 Edges pada SNA}

3) Diameter merupakan jarak maksimal antar node. Pada gambar 2.7, menjelaskan bahwa diameter pada jaringan tersebut adalah 3 . Hal ini menunjukkan berapa lama waktu yang dibutuhkan untuk mencapai node manapun dalam jaringan (Cheliotis, 2010).

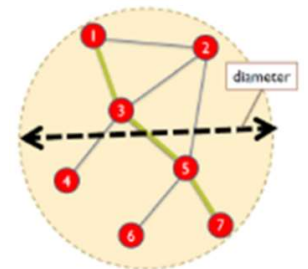

Gambar 4 Diameter pada SNA

4) Average Degree. Degree sendiri diartikan sebagai jumlah hubungan yang dimiliki sebuah node (Newman, 2018). Sehingga Average Degree dapat diebut juga dengan rata - rata jumlah hubungan yang dimiliki sebuah node.

5) Average Path Length. Path memiliki arti urutan nodes yang saling berjajar terhubung dengan edges membentuk sebuah jalur. Length memiliki makna yaitu jumlah edges yang dilalui sepanjang Path (jalur). Sehingga Average Path Length disebut dengan rata rata panjang jalur yang dilalui informasi dalam sebuah jaringan. Satuan yang digunakan adalah "hop". (Newman, 2018)

Untuk menentukan pemeran kunci diperlukan suatu alat ukur yang disebut dengan centrality. Terdapat banyak penelitian yang mengartikan centraliy. (Campbell, et al., 2013) Centrality memiliki fungsi untuk menentukan "node mana yang berperan paling penting atau sentral dalam sebuah jaringan?" Ada empat jenis penghitungan centrality yang sering digunakan, antara lain sebagai berikut:

1) Degree Centrality adalah jumlah edges (hubungan) yang terhubung dengan sebuah node. Terdapat dua Degree centrality, yaitu inDegree dan out-Degree. In-Degree adalah jumlah ikatan atau hubungan yang mengarah ke node (aktor), dan out-Degree adalah jumlah hubungan yang diarahkan kepada node lain (Newman, 2018).

2) Betweenness Centrality adalah cara untuk mengukur seberapa sering sebuah node terletak di jalur antara dua node lainnya. Node tersebut biasa dianggap sebagai "jembatan" yang jika menghapus seseorang (node) tersebut akan mengganggu hubungan antara orang lain didalam jaringan (Newman, 2018)

3) Closeness Centrality adalah pengukuran yang rata-rata jumlah langkah yang diperlukan oleh seorang aktor untuk menjangkau orang lain dalam jaringan. Seorang aktor yang memiliki kedekatan sentralitas yang tinggi adalah aktor yang paling efisien untuk melakukan kontak dengan orang lain dalam jaringan. Dengan kata lain, semakin tinggi sentralitas kedekatan aktor, maka posisi aktor dalam penyebaran informasi kepada aktor-aktor lain semakin baik. (Newman, 2018)

4) Eigenvector Centrality adalah perhitungan derajat yang memberi nilai relatif pada suatu jaringan berdasarkan prinsip bahwa koneksi dengan node-node yang memiliki skor tinggi lebih berkontribusi pada skor node yang ingin kita ukur dibandingkan koneksi ke node yang memiliki skor kecil (Newman, 2018).

Adapun kerangka pemikiran pada penelitian ini adalah sebagai berikut : 


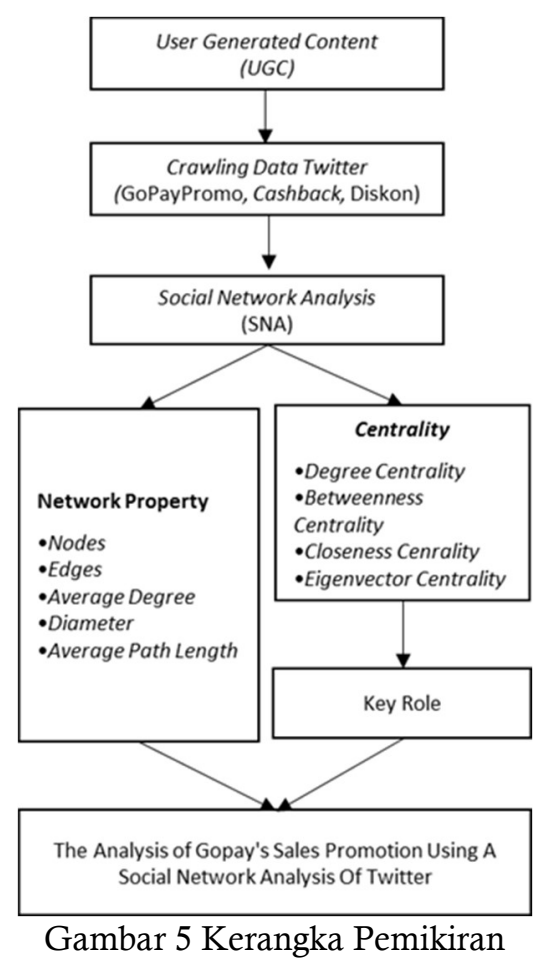

Penelitian ini menggunakan teknik analisis data social network analysis untuk mengetahui promosi penjualan Gopay dan hasil analisis jaringan sosial Gopay. Berikut proses teknik analisis data pada penelitian ini :

1. Pengumpulan Data: pengumpulan data dilakukan dengan melakukan crawling menggunakan aplikasi berbasis bahasa $\mathrm{R}$ yaitu $\mathrm{R}$ Studio yang terhubung dengan Twitter API. Tweet yang diambil mengandung kata kunci "Cashback Gopay dan Diskon Gopay" yang selanjutnya akan dilakukan preprocessing.

2. Preprocessing Data: tweet, mention, reply dan retweet kotor yang sudah terkumpul kemudian dilakukan preprocessing untuk menghilangkan tweet yang tidak relevan agar lebih mudah untuk dilakukan proses analisis. Selanjutnya menentukan aktor yang berinteraksi pada setiap tweet untuk dijadikan sebagai node dalam social network.

3. Pembuatan Model Jaringan: data yang sudah melalui preprocessing kemudian diproses kembali menggunakan aplikasi Gephi untuk dibuat visualisasi model jaringannya.
4. Identifikasi Properti Jaringan: setiap model jaringan yang sudah diproses dengan aplikasi Gephi memiliki beberapa properti yang akan dihitung nilainya. Adapun properti jaringan yang akan dihitung nilainya adalah: Nodes, Edges, Average Degree, Diameter dan Average Path Length.

5. Analisis centrality pada masing - masing kata kunci. Centrality yang dianalisis adalah : Degree Centrality, Betweenness Centrality, Closeness Centrality, dan Eigenvector Centrality

\section{Hasil dan Pembahasan}

Jaringan sosial yang telah berhasil di ciptakan dapat divisualisasikan seperti gambar dibawah ini.

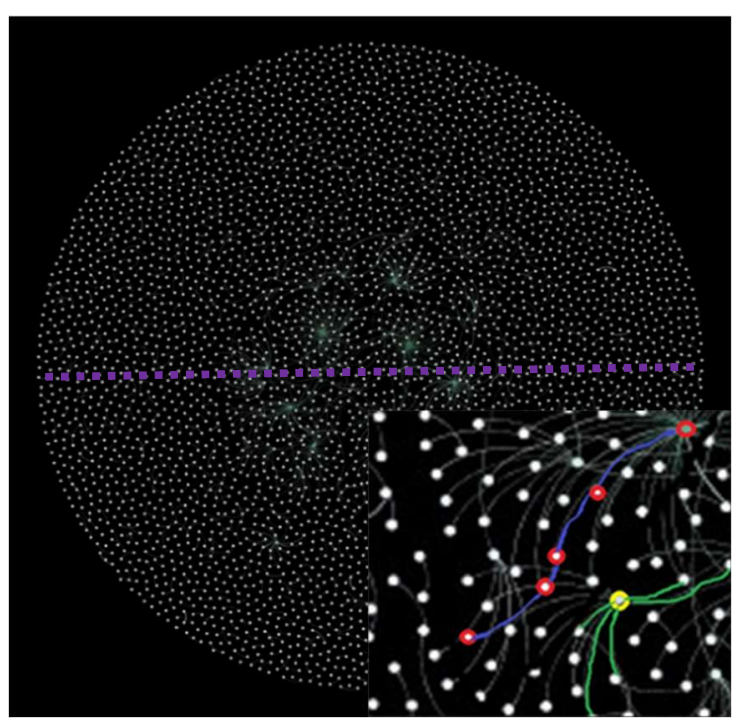

Gambar 6 Visualisasi Jaringan Promosi Penjualan Gopay di Twitter

Visualisasi di atas adalah model jaringan promosi penjualan Gopay di Twitter. Gambar tersebut mewakili pengguna Twitter yang mencuitkan promosi penjualan Gopay. Interaksi pengguna dalam studi ini diambil dalam rentang 12 November 2019-3 Desember 2019 dengan kata kunci "Cashback Gopay dan diskon Gopay".

Titik putih (node) dalam jaringan menunjukkan setiap aktor atau simpul yang berbicara tentang promosi penjualan Gopay dengan kata kunci "CashbackGopay dan 
DiscountGopay". Garis tipis yang ada diantara satu node dengan node lainnya, menunjukkan hubungan yang terbangun dalam jaringan tersebut. Garis ungu yang melintang dari sisi kanan hingga sisi kiri jaringan disebut dengan diameter jaringan. Garis biru merupakan contoh jalur (path) yang dilalui informasi hingga sampai pada node terakhir. Sedangkan garis - garis hijau yang dimiliki oleh node berwarna kuning menunjukkan keterhubungan yang dimiliki node tersebut. Tabel di bawah ini menunjukkan setiap nilai properti dalam jaringan sosial Gopay.

Hasil analisis jaringan sosial adalah peran kunci dari penyebaran informasi. Analisis jaringan pada akhirnya akan menginformasikan pemeran kunci dalam penyebaran informasi promosi penjualan Gopay di media sosial. Berikut adalah lima pengguna dengan nilai centrality tertinggi, yaitu:

Tabel 1. Nilai Centrality Pemeran Kunci

\begin{tabular}{|l|c|c|c|c|c|}
\hline & @Princkess & @Gojekindonesia & @PamerDiskon & @FOODFESS2 & @holtmeat_id \\
\hline $\begin{array}{l}\text { Degree } \\
\text { Centrality }\end{array}$ & $\mathbf{6 8}$ & 55 & 49 & 46 & 59 \\
\hline $\begin{array}{l}\text { Betweenness } \\
\text { Centrality }\end{array}$ & 14,75 & $\mathbf{1 9 , 1}$ & 4,51 & 3,5 & 9,78 \\
\hline $\begin{array}{l}\text { Closeness } \\
\text { Centrality }\end{array}$ & $\mathbf{0 , 4 2}$ & 0,35 & 0,31 & 0,26 & 0,23 \\
\hline $\begin{array}{l}\text { Eigenvector } \\
\text { Centrality }\end{array}$ & $\mathbf{1}$ & 0,71 & 0,62 & 0,49 & 0,42 \\
\hline
\end{tabular}

Sumber : Hasil Olah Data Penulis, 2020

Tabel diatas menunjukkan lima akun dengan nilai sentralitas tertinggi. Berdasarkan sentralitas pada Degree Centrality terdapat @princkess dengan nilai tertinggi, pada Betweenness sentrality ada@Gojekindonesia, pada Closeness centrality ada@princkess, pada Eigonvector Centrality ada @princkess.

\section{Pembahasan Hasil Penelitian}

Tabel 2. Hasil Perhitungan Properti Jaringan Gopay

\begin{tabular}{|c|c|c|}
\hline No & Properti Jaringan & Nilai \\
\hline 1 & Nodes & 4.021 \\
\hline 2 & Edges & 2.358 \\
\hline 3 & Average Degree & 1,175 \\
\hline 4 & Diameter & 14 \\
\hline 5 & Average Path Length & 5,07 \\
\hline
\end{tabular}

Sumber : Hasil Olah Data Penulis, 2020

Node adalah representasi dari aktor (pengguna) dalam jaringan sosial. Gambar 5 menunjukkan bahwa ada 4.021 aktor yang berinteraksi di jaringan sosial Gopay. Jumlah edge (hubungan) pada jaringan sosial adalah 2.358 lebih sedikit daripada node, ini berarti bahwa tidak semua node dalam jaringan terhubung antara satu node dan node lain tetapi masih tetap membentuk sebuah jaringan. Sebagaimana (Bratawisnu \& Alamsyah, 2018) mengatakan dalam jurnalnya, dapat disimpulkan pembicaraan tentang promosi penjualan Gopay di Twitter kurang aktif, sebab edge yang diartikan sebagai keterhubungan antar node lebih sedikit dibandingkan dengan node itu sendiri, dengan pembicaraan yang kurang aktif maka penyebaran informasi pun dapat menjadi kurang efektif.

Average Degree menunjukkan jumlah rata-rata keterhubungan dari sebuah node dengan yang lain. Pada jaringan sosial gopay node memiliki keterhubungan rata dengan node lain adalah 1,175 derajat. Menunjukkan bahwa 1 aktor hanya terhubung ke 1 aktor lain dalam jaringan. Mengacu pada (Aini \& Alamsyah, 2016) semakin banyak jumlah keterhubungan sebuah node maka penyebaran informasi mengenai promosi penjulan akan semakin cepat. Diameter adalah jarak terjauh antara 2 node. Dalam jaringan sosial Gopay diameter jaringannya adalah 14. Mengacu pada (Bratawisnu \& Alamsyah, 2018), semakin kecil diameter jaringan maka penyebaran informasi lebih cepat antara aktor. 
Terdapat pengukuran lain selain diameter untuk mengukur kecepatan penyebaran informasi pada jaringan sosial adalah Average Path Length, yang merupakan jarak rata - rata antara node pada jaringan. Satuan jarak pada jaringan biasanya disebut sebagai "hop ". Panjang jalur rata pada jaringan sosial Gopay adalah 5,07. Menunjukkan informasi melewati 5 hop untuk menjangkau pengguna lain.

Analisis jaringan sosial mengarahkan kita pada pemeran kunci yang menyebarkan informasi tentang promosi penjualan Gopay. @ Princkess memiliki jumlah koneksi tertinggi di antara pengguna lain yaitu 68, sehingga penyebaran informasi melaluinya akan lebih cepat.@Gojekindonesia memiliki peran sebagai jembatan informasi tertinggi di antara pengguna lain yaitu 19,1 jika pengguna ini menghilang maka penyebaran informasi akan terganggu. (a) princkess memiliki jarak terdekat dengan pengguna lain, sehingga penyebaran informasi juga akan lebih cepat. @princkess juga memiliki jarak terdekat dengan pengguna yang paling penting, sehingga dapat menjadi kunci untuk menyebarluaskan informasi. Berdasarkan hasil sentralitas@prinkess memiliki 3 sentralitas yang tertinggi antara lain.

\section{Kesimpulan dan Saran Kesimpulan}

Mengacu pada hasil jaringan sosial Gopay, penelitian ini bisa menjadi evaluasi bahwa analisis properti jaringan Gopay memiliki hubungan yang kurang dari jumlah node yang ada menunjukkan bahwa pengguna yang berbicara tentang promosi penjualan Gopay kurang aktif di jaringan sosial. Hasil analisis jaringan sosial Gopay adalah bahwa akun dengan username (a) princkess adalah aktor kunci dalam menyebarluaskan informasi tentang promosi penjualan berdasarkan analisis sentralitas. Karena@prinkess memiliki nilai tertinggi pada 3 sentralitas yang menunjukkan informasi melalui akun akan dikirimkan lebih cepat daripada akun lain.

Gopay adalah pengguna yang paling aktif, hasilnya seharusnya lebih baik dari ini. Meskipun hasil kurang dari harapan, hal ini dapat disebabkan oleh keterbatasan yang terdapat pada penelitian ini, dimana hanya menggunakan sumber data sekunder UGC (user generated content) yang merupakan conversastion antara pengguna (menciak, balas, dan retweet), UGC hanya terkait dengan Cashback dan diskon, data yang dikumpulkan dari 12 November 2019 sampai 3 Desember 2019. Keterbatasan ini ada karena adanya batas energi, biaya, dan waktu.

\section{Saran Bagi Perusahaan}

Agar node dan edge jaringan sosial semakin meningkat, Perusahaan sebaiknya lebih aktif dalam menggunakan media social Twitter nya, dengan cara melakukan kegiatan posting tweet promosi penjualan yang lebih aktif dan atraktif, sehinga banyak user yang tertarik memulai percakapan yang akan mengindikasikan bahwa informasi tentang promosi penjualan telah tersampaikan karena adanya feedback.

Perusahaan juga sebaiknya melakukan sebuah kegiatan yang akan meningkatkan nilai properti jaringan seperti melakukan kompetisi bagi user yang memposting twet tentang promosi penjualan Gopay yang terbaru dan memiliki banyak like, retweet, dan reply maka akan diberikan semacam voucher untuk melakukan kegiatan lain di aplikasi Gojek. Dengan adanya kegiatan ini, penyebaran informasi tentang promosi tersebut berjalan dengan baik, begitu pula dengan engagement yang akan terbentuk juga semakin erat.

Perusahaan dapat melakukan endorsement kepada key actor atau pemeran utama di jaringan sosial untuk menyebarkan informasi tentang promosi penjualan yang dilakukan Gopay, yaitu akun dengan username@princkess, sebab memiliki tiga nilai centrality tertinggi.

\section{DAFTAR PUSTAKA}

Aini, V. N., \& Alamsyah, A. (2016, April 1). Analisis Pada Peringkat Top Brand Menggunakan Jejaring Sosial Percakapan Dengan Social Network Analysis ( Studi Kasus Pada Smartphone Samsung, Blackberry, Nokia, Iphone Di Indonesia) . e-Proceeding of Management, pp. 77-85.

Alawan, A. A., Rana, N. P., Dwivedi, Y. K., \& Algharabat, R. (2017). Social Media in 
Marketing : A Review and analysis of the existing literature. Telematics and Informatics, 34(7), 1177-1190.

Anggraeni , L. (2019, August 19). Go-Pay Jadi Dompet Digital Paling Populer di Indonesia. Retrieved September 25, 2019, from https://www.medcom.id/teknologi/ne ws-teknologi/0Kv9o5pk-go-pay-jadidompet-digital-paling-populer-diindonesia

Ashley, C., \& Tuten, T. (2015). Creative Strategies in Social Media Marketing : An Exploratoryon Branded Social Content and Consumer Engagement. Psychology and Marketing Journal, 15-27.

Bratawisnu, M. K., \& Alamsyah, A. (2018). Dynamic Social Network Analysis Untuk Analisa Interaksi User Di Media Sosial Mengenai Bisnis. Jurnal Almana: Manajemen dan Bisnis, II(2), 107-115.

Campbell, W., Weinstein, C. J., \& Dagli, C. K. (2013). Social Network Analysis With Content and Graph. Lincoln Laboratory Journal, 20(1), 62-81.

Cheliotis, G. (2010). Social Network Analysis . Singapore: National University of Singapore.

Hanneman, R. A., \& Riddle, M. (2005). Introduction to Social Network Methods (1st ed.). Riverside US: University of California.

Ishikawa, H. (2015). Social Big Data Mining (1st ed.). Boca Raton: CRC Press.

Mileva, L., \& Fauzi, A. (2018). Pengaruh Social Media Marketing terhadap keputusan pembelian (Survei Online pada mahasiswa Sarjana Jurusan Ilmu Administrasi Bisnis Angkatan 2014/2015 Fakultas Ilmu Administrasi Universitas Brawijaya yang Membeli Starbucks Menggunakan LINE). Jurnal Administrasi Bisnis, LVVII(1), 190-199.

Moens, M. F., Juanzi, L., \& Chua, T. S. (2014). Mining User Generated Content (1st ed.). Bora Raton: CRC Press.

Newman, M. (2018). Network (2nd ed.). New York: Oxford University Press Inc.

Sugiyono. (2014). Metode Penelitian Kuantitatif, Kualitatif, dan R\&D. Bandung: CV. Alfabeta.

Zainuri, A., Astuti, E. S., \& Dewantara, R. Y. (2015). Pengaruh Kemudahan Penggunaan Dan Kemanfaatan Teknologi Informasi Berbasis Wireless Terhadap Niat Pengguna Internet (Studi pada Pengguna Akses Indonesia Wifi (wifi.id) PT. Telekomunikasi Indonesia,
Tbk. Kandatel Lamongan). Jurnal Administrasi Bisnis, 9. 